\title{
Alguns aspectos da noção da congruência semântica presentes no ensino dos números inteiros relativos ${ }^{1}$
}

\author{
Selma Felisbino Hillesheim* \\ Méricles Thadeu Moretti**
}

\section{Resumo}

O ensino dos números negativos é fortemente impregnado por um ensino baseado no modelo comercial da perda e do ganho em que a perda se relaciona à operação de subtração e o ganho, à de adição. Essa "espécie de quase codificação" na associação às operações de adição e subtração traz à tona um fenômeno estudado por Raymond Duval, na aprendizagem matemática, denominado congruência semântica. Nas situações de ensino, as concepções das operações de adição, multiplicação e subtração precisam ser ampliadas dos naturais aos números relativos. No que se refere a essa ampliação de ensino, neste artigo, analisam-se as respostas, com base na noção de congruência semântica, de uma turma de alunos do $7^{\circ}$ ano do ensino fundamental a algumas questões propostas.

Palavras-chave: Congruência semântica. Números negativos. Registros de representação.

\section{Introdução}

No Brasil, os números inteiros relativos são apresentados formalmente aos alunos no $7^{\circ}$ ano $^{2}$, e muitas dificuldades podem ser percebidas no seu processo de ensino e aprendizagem. A não compreensão desse conceito e sua repercussão ao longo da trajetória estudantil têm preocupado professores de matemática e pesquisadores (COQUIN-VIENNOT, 1985; PASSONI, 2002; PONTES, 2010; ALVES; MAIA, 2011) que buscam explicações para as dificuldades encontradas no processo de ensino e aprendizagem desses números, bem como procuram outros modelos de ensino para os números inteiros. Nessa perspectiva, este artigo, que faz parte de

Recebido em $1^{\circ}$ de outubro de 2012. Aprovado em 15 de janeiro de 2013.

http://dx.doi.org/10.5335/rep.2013.3511

Licenciada em Ciências e mestranda do PPGECT/UFSC. Membro do grupo de pesquisa GPEEM. Professora de matemática do estado de Santa Catarina. E-mail: selmafh@yahoo.com.br.

* Doutor em Didática da Matemática. Líder do grupo de pesquisa GPEEM. Professor do PPGECT/UFSC. E-mail: mthmoretti@gmail.com. 
uma dissertação de mestrado em andamento, pretende analisar as respostas, com base na noção de congruência semântica, de uma turma de alunos do $7^{\circ}$ ano do ensino fundamental a algumas questões propostas durante a fase de experimentação da nossa pesquisa.

Os alunos chegam ao $7^{\circ}$ ano associando a ideia de número a uma grandeza, o que pode ser percebido nos mais variados assuntos contemplados no currículo das séries iniciais do ensino fundamental e do $6^{\circ}$ ano. Até o $6^{\circ}$ ano, operações do tipo $\mathrm{a}-\mathrm{b}$ somente podem ser resolvidas se $\mathrm{a} \geq \mathrm{b}$, pois é impossível conceber a ideia de se tirar, por exemplo, sete balas de um pacote que tinha apenas cinco balas. "A perturbação se instala quando a subtração $(a-b)$ é aplicada a casos em que $b>a$, gerando um resultado até então inexistente e demonstrando assim o caso típico em que as formas (operações) geram um novo conteúdo" (TEIXEIRA, 1993, p. 62). Nesse caso, o novo resultado implica reconhecer um novo tipo de número: os negativos.

No conjunto dos números inteiros relativos, as concepções que os alunos trazem sobre as operações de adição e subtração simplesmente caem por terra, uma vez que, nesse novo contexto, adicionar nem sempre representa um aumento, assim como subtrair nem sempre representa diminuir. Para Teixeira (1993), o conceito de adição deve ser ampliado no conjunto dos números inteiros relativos, não podendo mais se limitar à ideia de acrescentar. Da mesma forma, "subtrair inteiros significa trabalhar com operadores negativos, ou seja, números que operam transformações de oposição" (TEIXEIRA, 1993, p. 64). Por exemplo, $-4-(-5)=-4+5$ ou, ainda, $-4-(+5)=-4-5$.

Com base nessa mesma linha de pensamento das operações com números inteiros relativos, a multiplicação no conjunto dos números inteiros não pode mais ser completamente compreendida como uma adição de parcelas iguais. Com efeito, seguindo esse caminho, de acordo com Teixeira (1993, p. 65), a multiplicação encontra um obstáculo: como mostrar que $(-1) \times(-1)=1$ ?

Para que o aluno consiga lidar com essas situações, podendo dominar as operações com números inteiros relativos, faz-se necessário que ele amplie o seu conceito de número. "A construção do conceito de número inteiro, do ponto de vista matemático, é uma ampliação dos naturais, sendo desta perspectiva necessário demonstrar que as leis do sistema de numeração seguem sendo cumpridas” (TEIXEIRA,1993, p. 62).

No nível de aprendizagem, essas ampliações e ressignificações das operações dos naturais para os relativos requerem uma atenção especial. Para tanto, podemos pensar no sentido da congruência semântica apresentada por Raymond Duval por meio da sua teoria dos registros de representação semiótica. 


\section{Os registros de representação semiótica}

$\mathrm{Na}$ teoria dos registros de representação semiótica, o estudo da matemática se estabelece com base em representações, pois os objetos matemáticos, não sendo acessíveis pela percepção, o fazem pela representação. Dessa forma, surge a necessidade de um sistema de representação semiótico para poder dar representantes aos objetos matemáticos e com eles se operar.

Porém, é imprescindível salientar "[...] o entendimento de que nenhum dos registros de representação 'é' o objeto matemático, mas eles apenas o 'representam', estão 'no lugar dele' para, assim, permitir o acesso a esses objetos matemáticos" (COLOMBO; FLORES; MORETTI, 2008, p. 45). Nesse sentido é que Duval chama a atenção para o paradoxo cognitivo do pensamento matemático:

[...] de um lado, a apreensão dos objetos matemáticos só pode ser uma apreensão conceitual e, de outro, é somente pelo meio de representações semióticas que uma atividade sobre os objetos matemáticos é possível. [...]. Como sujeitos, em fase de aprendizagem, poderiam não confundir os objetos matemáticos com suas representações semióticas se eles só podem tratar com representações semióticas? (1993, p. 38, tradução nossa).

Muitas vezes, no ensino, não damos a devida importância ao paradoxo cognitivo do pensamento matemático devido ao fato de estarmos mais atentos às representações mentais do que às representações semióticas. Segundo Duval, as representações mentais dizem respeito "[...] às conceitualizações que um indivíduo pode ter sobre um objeto", ao passo que as representações semióticas "[...] são produções constituídas pelo emprego de signos pertencentes a um sistema de representações que tem seus embaraços próprios de significação e de funcionamento" (1993, p. 39).

Ainda, de acordo com Duval, essas representações semióticas não servem somente para fins de comunicação, sendo, também, essenciais para as atividades cognitivas do pensamento. Nessa perspectiva, os registros de representação semiótica são fundamentais tanto para a criação de objetos matemáticos como para a sua apreensão.

Numa aula de matemática, por exemplo, o 2, objeto externo, é utilizado para estabelecer a relação com as noções e ideias do conceito desse número. Dessa forma, o emprego do signo é como um instrumento internalizado, operado em nível mental. Assim, dois deslocamentos à esquerda na reta dos números inteiros, a temperatura de dois graus abaixo de zero, dois metros de profundidade são instrumentos externos. As respectivas representações são signos internos.

Dentre a diversidade de representações semióticas, Duval (2005) estabelece quatro grandes grupos de registros, a saber: a linguagem natural, as escritas algébricas e formais, as figuras geométricas e as representações gráficas. Segundo o 
teórico (1993), para que possa ser considerado um registro de representação, o sistema semiótico deve promover três atividades cognitivas fundamentais ligadas à semiose: a formação de uma representação identificável, o tratamento e a conversão.

a) A formação de uma representação identificável, de um modo geral, corresponde a regras de conformidade que já se encontram estabelecidas, de forma que não é competência do sujeito criá-las, mas apenas usá-las para reconhecer as representações. Nesse sentido, não cabe aos nossos alunos criar o conjunto dos números relativos, senão apropriar-se dele e de suas regras de conformidade para a construção das operações fundamentais.

b) O tratamento de uma representação é a transformação interna a um registro, ou seja, é a transformação dessa representação dentro do registro onde ela foi formada. Por exemplo, quando trabalhamos com a operação de adição de números relativos, o tratamento exige a compreensão das regras algorítmicas próprias desses números.

c) A conversão é a transformação de uma representação dada em um registro, em uma representação de um outro registro, mantendo os mesmos objetos revelados, de maneira a conservar a sua totalidade, ou apenas uma parte do conteúdo da representação inicial. Não podemos, de forma alguma, confundir a conversão com o tratamento. A conversão se estabelece entre registros diferentes, enquanto o tratamento acontece dentro do mesmo registro. Por exemplo, passar a representação da operação numérica $(-3)+(+5)$ para uma representação geométrica na reta dos inteiros indica uma conversão. Ilustrando:

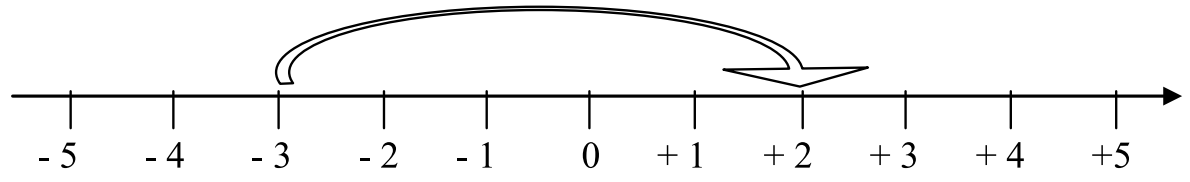

Fonte: Figura elaborada pelos autores.

Figura 1: Representação geométrica da adição $(-3)+(+5)$

A conversão não tem um papel de prova ou justificação nos processos matemáticos. Talvez por esse motivo não desperte tanto a atenção nesses processos.

[...] como se se tratasse somente de uma atividade lateral, evidente e prévia à "verdadeira" atividade matemática. Mas, do ponto de vista cognitivo, é a atividade de conversão que, ao contrário, aparece como a atividade de transformação representacional fundamental, aquela que conduz aos mecanismos subjacentes à compreensão (DUVAL, 2005, p. 16).

Assim, de acordo com esse autor, a essência da atividade matemática repousaria na mobilização simultânea de ao menos dois registros de representação ao 
mesmo tempo. Baseado nesse raciocínio, Duval levanta a hipótese de que a compreensão em matemática supõe a coordenação de, no mínimo, dois registros de representações semióticas. Nas palavras do teórico, "a compreensão da matemática implica a capacidade de mudar de registro" (2005, p. 21). Percebemos, então, em consonância com o autor, que é no trânsito entre esses diversos registros de representação que se encontra a "chave" para a aprendizagem em matemática.

\section{Congruência semântica e a atividade de conversão}

Um dos obstáculos encontrados por muitos alunos nas suas aprendizagens matemáticas está ligado ao fato de que a equivalência referencial se destaca da congruência semântica. Sobre esse assunto Duval esclarece: "Duas expressões podem ser sinônimas ou referencialmente equivalentes (elas podem 'querer dizer a mesma coisa', elas podem ser verdadeiras ou falsas ao mesmo tempo) e não serem semanticamente congruentes: neste caso, há um custo cognitivo importante para a compreensão" (2012, p. 100).

Geralmente, quando ocorre a passagem de uma representação semiótica a outro sistema de maneira espontânea, diz-se que há congruência semântica. Para isso ela deve, de acordo com Duval (2004, p. 53), atender a três condições:

1. correspondência semântica entre as unidades significantes que as constituem;

2. univocidade "semântica" terminal, em que cada unidade significante elementar de partida corresponde a uma só unidade significante elementar no registro de chegada;

3. a ordem dentro da organização das unidades significativas de partida é mantida na representação de chegada.

Quando um desses critérios deixa de ser cumprido, as representações não são congruentes entre si, e a passagem de um sistema de representação a outro não ocorre de imediato (DUVAL, 2004, p. 17). Poderíamos dizer, "grosso modo", que há congruência semântica quando o aluno reconhece facilmente o objeto matemático, ao passo que, quando esse reconhecimento não ocorre tão facilmente, não há congruência semântica. Dessa forma, o problema da congruência ou da não congruência semântica de duas apresentações de um mesmo objeto é a distância cognitiva entre essas duas representações. Quanto maior a distância cognitiva, maior será o custo de passagem de uma representação semiótica a outra e maior será, também, o risco de o processo matemático não ser efetuado ou entendido pelos alunos.

Vejamos um exemplo que poderá nos ajudar a entender melhor o caso da congruência semântica apresentada por Duval: 
Paulo tem 10 figurinhas e perdeu 3 em uma partida...

Nesse exemplo, destacamos a identidade entre a frase e a expressão 10 - 3, onde o verbo "perdeu" pode ser facilmente associado à operação de subtração. Percebemos que a ordem da apresentação dos dados numéricos na frase é conservada na mesma ordem da operação. Assim, podemos dizer que existe a congruência semântica entre a frase e a expressão. Nesse caso, pode ser notada, igualmente, a equivalência referencial entre a frase e a expressão aritmética.

Imaginemos, agora, a seguinte situação-problema: "No início de uma tarde de inverno de uma cidade da serra catarinense, os termômetros registraram $4^{\circ} \mathrm{C}$ e, no início da noite, -2 $\mathrm{C}$. Qual a variação da temperatura nesse período?” Essa situação possui congruência semântica com a expressão $(+4)+(-2)$. Entretanto, a situação e a expressão não são referencialmente equivalentes. A situação descrita acima não possui congruência semântica com a expressão (-2) - (+4), contudo, a situação e a expressão aritmética são referencialmente equivalentes e conduzem a resolução correta do problema. "Duas expressões diferentes podem ser referencialmente equivalentes sem que sejam semanticamente congruentes. Inversamente, duas expressões podem ser semanticamente congruentes sem que sejam referencialmente equivalentes" (DUVAL, 2012, p. 100).

Ainda nesse sentido, Moretti aponta para os reflexos da congruência semântica no ensino:

Problemas discursivos que são semanticamente congruentes com a expressão matemática, mas que não são referencialmente equivalentes, levam a uma taxa muita baixa de sucesso; da mesma forma acontece com problemas que são referencialmente equivalentes, mas não são semanticamente congruentes. A resolução de problemas que solicitam a passagem de um registro discursivo para um registro aritmético ou algébrico exige a equivalência referencial (2012, p. 705).

Nessa direção, o professor deve ficar atento ao fato de que nem sempre a congruência semântica conduz a resultados bem-sucedidos na resolução de problemas matemáticos. Além disso, produzindo diferentes formulações para um mesmo problema, poderá contribuir para uma verdadeira compreensão matemática.

Dois fenômenos podem ser observados, no que se refere à natureza cognitiva, nas operações de conversão. O primeiro diz respeito às variações de congruência semântica, já expostas anteriormente, e o segundo, à heterogeneidade dos dois sentidos de conversão. "Nem sempre a conversão se efetua quando se invertem os registros de partida e de chegada" (DUVAL, 2005, p. 20).

Segundo Duval (2005), no ensino da matemática, na maioria das vezes, um sentido de conversão é privilegiado, reforçando a falsa ideia de que o treinamento 
realizado num sentido estaria, automaticamente, exercitando a conversão no outro sentido. Essa é uma visão muito ingênua que se propaga nas situações de ensino da matemática. Na maior parte dos casos, os estudantes não conseguem perceber o mesmo objeto matemático representado em sistemas semióticos diferentes. Por exemplo, em se tratando da representação do cálculo de uma adição de números relativos e da sua representação por meio de deslocamentos na reta numérica, dificilmente um aluno em nível de ensino fundamental e até mesmo médio consegue estabelecer as relações entre o cálculo e a sua representação geométrica na reta numérica, e vice-versa.

Ainda em conformidade com esse autor, os diferentes registros de representação se completam, proporcionando-nos uma melhor compreensão do objeto matemático. A aprendizagem de um objeto matemático torna-se significativa quando o aluno, além de realizar os tratamentos em diferentes registros de representação, consegue naturalmente converter um registro de representação em outro. Do ponto de vista cognitivo, de acordo com Duval (2005), a atividade de conversão é essencial na condução à compreensão.

Contudo, também em consonância com o autor, esse processo não se estabelece tão facilmente, tendo em vista que os alunos apresentam muita dificuldade no estudo da matemática. Em determinadas situações, eles até conseguem representar um objeto matemático de maneiras diferentes, mas são incapazes de fazer as conversões necessárias para a apreensão desse objeto.

Ao fazer uma análise do desenvolvimento dos conhecimentos e dos obstáculos encontrados nas representações do raciocínio, Duval (2004) ressalta que as barreiras encontradas pelos alunos na compreensão de textos e na aquisição de tratamentos lógicos e matemáticos podem ser compreendidas por meio de três fenômenos que estão estreitamente ligados.

O primeiro corresponde aos vários registros de representação semiótica. No ensino da matemática, dispomos de uma variedade de registros de representação semiótica: a linguagem natural, a linguagem simbólica, as figuras geométricas, os gráficos. Estes não podem ser considerados um mesmo tipo de registro, pois são sistemas de representações muito diferentes, atuando cada um de maneira particular sobre a aprendizagem. Mais especificamente, no caso dos números relativos, dispomos de uma variedade de registros para representar um mesmo objeto. Por exemplo, a frase "Pela manhã, os termômetros registraram - 2 C, com o passar do dia as temperaturas subiram $7^{\circ} \mathrm{C}^{\prime}$ pode ser representada tanto pela expressão $(-2)+(+7)$ quanto por um deslocamento na reta numérica: 


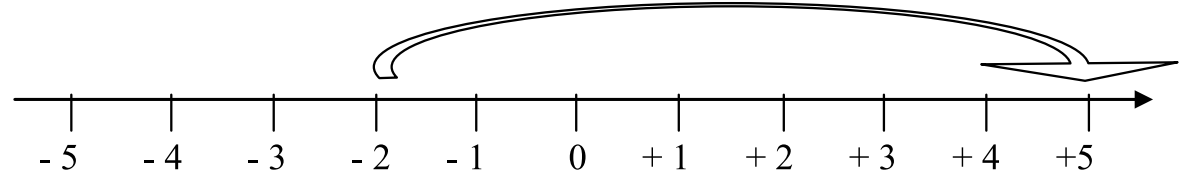

Fonte: Figura elaborada pelos autores.

Figura 2: Representação geométrica da adição $(-2)+(+7)$

Nesse exemplo, apresentamos o mesmo objeto matemático utilizando três registros de representação semiótica diferentes, a linguagem natural representada pela frase, a linguagem simbólica utilizada no cálculo e a representação geométrica apresentada na reta numérica.

O segundo fenômeno, de acordo com Duval (2004), refere-se à diferenciação entre o representante e o representado, em outras palavras, à diferença existente entre a forma e o conteúdo de uma representação semiótica. A forma escolhida para representar o objeto matemático influencia no conteúdo da sua representação. Conforme o autor, embora possam fazer referência a um mesmo objeto, as duas expressões não possuem a mesma significação, haja vista que não são reveladoras do mesmo domínio de descrição ou do mesmo ponto de vista. As diferentes formas de representar um objeto matemático permitem exibir propriedades também diferentes desse objeto, mantendo a mesma referência. No exemplo que citamos acima, podemos perceber que, apesar de representarem o mesmo objeto, os três registros utilizados possuem significações diferentes.

Duval ressalta a complementaridade dos registros, afirmando que "[...] toda representação é cognitivamente parcial em relação ao que ela representa e que de um registro a outro não estão os mesmos aspectos do conteúdo de uma situação que são representados" (1993, p. 48, tradução nossa). Desse modo, a variedade de registros utilizados para o ensino de um objeto matemático poderá contribuir para que se tenha uma ideia global a seu respeito, permitindo que o aluno não confunda o objeto com a sua representação.

$\mathrm{O}$ terceiro fenômeno diz respeito à coordenação entre os diferentes registros de representação semiótica. Para efetuar a conversão de um sistema semiótico em outro, não bastam regras de correspondência, mesmo porque, se existisse uma regra, não seria conversão. O maior obstáculo que se instala na realização espontânea da coordenação dos diferentes registros de representação semiótica está relacionado ao fenômeno da não congruência semântica. No exemplo que citamos há pouco, dificilmente um aluno estabelece uma relação direta entre o cálculo e a sua representação na reta numérica, uma vez que não há uma congruência semântica. 
Para analisarmos as dificuldades encontradas no processo de ensino e aprendizagem da matemática, precisamos estudar a conversão das representações, os procedimentos cognitivos que levam o aluno à apreensão do objeto matemático. A articulação de diferentes registros, de acordo com Duval (2005), é uma condição necessária para a compreensão em matemática. No entanto, várias abordagens didáticas não levam isso em conta, porque o que chama a atenção nos processos de ensino são os tratamentos, e não a conversão.

\section{A congruência semântica e as operações de adição, subtração e multiplicação com os números inteiros relativos}

$\mathrm{Na}$ atividade matemática, o ato de substituir uma fórmula ou um cálculo por outra expressão referencialmente equivalente é essencial. Você já pensou na possibilidade de resolver uma situação-problema sem substituí-la por outra forma de registro, permanecendo somente na linguagem natural? Nesse sentido, a substitutividade de expressões é uma propriedade que está ligada à estrutura de todo registro semiótico, sendo, portanto, uma conduta muito importante e frequente nos procedimentos matemáticos.

Os procedimentos utilizados na atividade matemática implicam uma substitutividade tanto inter-registro quanto intrarregistro, ambos pautados numa mesma referência. Conforme Duval, "a substitutividade é uma característica fundamental do funcionamento cognitivo do pensamento matemático, e é relativamente a esta substitutividade que os fenômenos de congruência e não congruência semântica são importantes" (2012, p. 113).

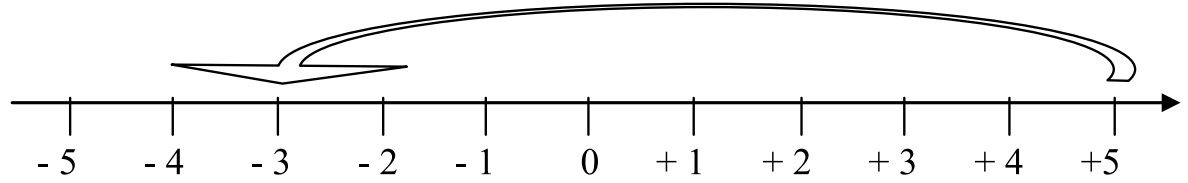

Fonte: Figura elaborada pelos autores.

Figura 3: Representação geométrica da adição $(+5)+(-8)$

Para mostrar, por exemplo, que o deslocamento da reta pode ser representado pela operação $(+5)+(-8)$, foi necessária uma substituição inter-registro, que não apresenta uma congruência semântica com a sua representação geométrica. A congruência semântica conduziria a expressão $(+5)+(-3)$, que, por sua vez, se diferencia da equivalência referencial. 
Nas operações com relativos é que os fenômenos de congruência semântica se destacam. Até a apresentação dos números inteiros, os alunos concebiam, nos naturais, que a adição estava rigorosamente atrelada à ideia de juntar. A subtração corresponderia à operação de tirar, e a multiplicação seria tomada como uma adição de parcelas iguais. Contudo, mesmo que esses conceitos sejam ampliados nos relativos, os fenômenos da não congruência semântica insistem em aparecer. Vejamos a seguinte situação, por exemplo: "Um submarino encontra-se a -250 metros de profundidade. Depois de passados 30 minutos encontra-se a -180 metros. Esse submarino subiu ou desceu? Quantos metros?". Essa expressão é referencialmente equivalente à expressão (-180) - (-250), o que resulta numa subida de 70 metros realizada pelo submarino. No entanto, a expressão que possui congruência semântica com a situação é (-250) - (-180), o que levaria ao resultado - 70, significando que o submarino desceu 70 metros.

Analisemos outra situação: "A temperatura registrada durante a madrugada, em uma cidade, foi de - $6^{\circ} \mathrm{C}$ e no decorrer do dia a temperatura aumentou para $10^{\circ}$ C. Qual foi a variação da temperatura máxima registrada nesse dia?”. Essa expressão é referencialmente equivalente à expressão $(-6)+(+10)$, o que indica que a temperatura máxima foi de $+4^{\circ}$. Entretanto, embora se tratasse de uma operação de adição, foi preciso diminuir os valores absolutos dos números para chegar ao resultado correto. Do ponto de vista da congruência semântica, não seria de se estranhar que um aluno chegasse ao resultado + 16, uma vez que a operação indicada é uma adição.

Entretanto, de acordo com Caraça, nos relativos tem-se que:

$\mathrm{a}+(-\mathrm{b})=a+(0-\mathrm{b})=a+0-b=a-b ; \mathrm{a}-(-\mathrm{b})=\mathrm{a}-(0-\mathrm{b})=a+\mathrm{b}-0=a+b$, isto é, somar um número negativo equivale a subtrair o número positivo com o mesmo módulo; subtrair um número negativo equivale a somar o número positivo com o mesmo módulo. No campo relativo, as duas operações aparecem-nos assim unificadas numa só, que se chama adição algébrica (1963, p. 101).

Desse modo, no caso dos relativos, a operação de adição pode representar situações em que há acréscimo ou decréscimo, ou mesmo somas que dão resultado zero. Assim, "a adição deixa de ser apenas acrescentar (um dos casos) para ter um novo significado, mais genérico, de associação ou composição” (TEIXEIRA, 1993, p. 64). Continua o autor, explicando que "[...] a construção operatória da subtração supõe assimilá-la como inversa à adição, de tal forma que em uma dada reunião ou associação de elemento $(\mathrm{a}+\mathrm{b}=\mathrm{c})$, é possível chegar ao ponto de partida, (a), por exemplo, pela diferença (c - b), , ou seja, pela operação inversa (TEIXEIRA, 1993, p. 64). 
No caso da multiplicação dos relativos, a barreira encontrada para o seu ensino apoia-se na ideia de que a multiplicação, nos naturais, é concebida como uma soma de parcelas iguais. Nos inteiros, a multiplicação de um número positivo por outro positivo, da mesma forma que a multiplicação de um número positivo por um número negativo, pode ser perfeitamente entendida como uma repetição de parcelas. Por exemplo, $(+3) \times(-5)$ pode ser concebido como três deslocamentos de (-5), o que resulta em -15. De igual modo, a multiplicação de dois números positivos, por exemplo, $(+4) \times(+2)$, pode ser entendida como quatro deslocamentos de $(+2)$, o que resulta em +8 . Esses exemplos, porém, esbarram num obstáculo quando se tenta explicar a multiplicação de dois números negativos.

A congruência semântica pode ser percebida na multiplicação dos relativos, principalmente, quando esses números estão associados ao modelo comercial3. Como uma dívida multiplicada por uma outra dívida pode se transformar num ganho? De acordo com Duval, o fenômeno da congruência semântica exerce um papel importante no interior de um mesmo registro, mais particularmente, no discurso natural. Assim, segundo o autor, "se a formulação da questão é congruente à formulação das informações dadas no enunciado do problema e se essa formulação é também congruente a uma formulação possível da resposta, esta resposta será mais rápida do que no caso da não congruência” (2012, p. 104).

Como relata Duval, a não congruência semântica se constitui como uma fonte de dificuldades para os alunos, independentemente do conteúdo matemático, uma vez que a

[...] atividade matemática pode ser bem-sucedida se a sua apresentação e seu desenvolvimento não exigirem alguma transformação entre as expressões de formulações ou de representações congruentes, e a mesma tarefa matemática dada como uma variante que implique uma manipulação de dados não congruentes pode conduzir ao insucesso (2012, p. 110).

Desse modo, a passagem da frase "o produto de dois números inteiros é + 10" para a expressão “(-2) × (-5)" exige uma manipulação de dados não congruentes e uma substitutividade inter-registro, passando da linguagem natural para a linguagem numérica ${ }^{4}$. Essa passagem envolve um custo cognitivo elevado, o que pode contribuir para um insucesso. De acordo com Duval, os problemas ligados à substituição inter-registro constituem um interesse particular para o ensino geral da matemática, pois “[...] aprender a articular vários registros de representação da informação e aprender a diferenciar diversos tipos de funcionamentos cognitivos poderão ser uma finalidade do ensino de matemática que se mostra interessante e útil aos não matemáticos" (2012, p. 116). 


\section{Análise de testes sob a perspectiva da noção de congruência semântica}

Apresentaremos, na continuidade, algumas questões que foram aplicadas numa turma de $7^{\circ}$ ano no início do ano letivo de 2012, durante a nossa pesquisa de mestrado, ainda em desenvolvimento. Nós elaboramos e aplicamos uma sequência didática em que as operações de adição, multiplicação e subtração de números inteiros foram apresentadas por meio do "princípio de extensão", e à luz da teoria dos registros de representação semiótica analisamos as situações em que o fenômeno da congruência semântica se destacou.

A turma era composta por 39 alunos, e a sequência didática abrangeu três etapas de ensino: operação de adição, multiplicação e subtração. No final de cada uma dessas etapas, foi aplicado um teste, cujo objetivo consistia em avaliar o nível de aprendizagem alcançado em cada fase da sequência didática. Com base nas respostas encontradas nesses testes, podemos observar como os fenômenos da congruência semântica estão fortemente presentes nas situações de ensino, principalmente, nos inteiros relativos.

A primeira questão que iremos analisar faz parte do teste aplicado no bloco da adição. $\mathrm{O}$ teste foi realizado por 36 dos 39 alunos que compõem a turma. A questão foi retirada do livro didático de matemática do Projeto Araribá, a saber: "Um caracol pretendia chegar ao topo de um muro; no entanto, subia alguns centímetros e escorregava outros". No primeiro item da questão, apresentava a seguinte situação: "Certa vez ele subiu $8 \mathrm{~cm}$ e escorregou $6 \mathrm{~cm}$. Houve avanço ou retrocesso? De quanto?” (2006, p. 28).

Essa questão foi respondida corretamente por quinze alunos, os quais alegaram que houve um avanço de dois centímetros; de forma parcialmente correta por dez alunos; e onze não a responderam corretamente. Dentre os alunos que a acertaram parcialmente, podemos constatar certa confusão entre os termos "avanço" e "retrocesso". Vejamos um exemplo:

\section{a) Certa vez ele subiu $8 \mathrm{~cm}$ e escorregou $6 \mathrm{~cm}$. Houve avanço ou retrocesso? De quanto? heresso cle $2 \mathrm{~cm}$}

Figura 4: Resposta apresentada pelo aluno 35

Esse aluno, apesar de ter realizado corretamente os deslocamentos necessários, chegando ao resultado +2 , associou tal posição final a um retrocesso, e não a um avanço, como indica o sinal de positivo.

Dentre os alunos que não responderam corretamente à questão, podemos perceber que eles se prenderam ao fato de o caracol ter escorregado $6 \mathrm{~cm}$, não levando em consideração o primeiro deslocamento, subindo $8 \mathrm{~cm}$. Vejamos um caso: 
a) Certa yez ele subiu $8 \mathrm{~cm}$ e escorregou $6 \mathrm{~cm}$. Houve avanço ou retrocesso? De quanto? Retrolese ols $6 \mathrm{~cm}$

Figura 5: Resposta apresentada pelo aluno 01

O segundo item dessa questão apresentava a seguinte situação: “Já em outra ocasião, ele subiu $9 \mathrm{~cm}$, escorregou $15 \mathrm{~cm}$ e subiu $4 \mathrm{~cm}$. Houve avanço ou retrocesso? De quanto?" (PROJETO Araribá, 2006, p. 28). Para essa questão, encontramos dez respostas corretas, identificando que houve um retrocesso de - 2; constatamos o mesmo número de respostas parcialmente corretas; quinze alunos não a responderam corretamente; e um simplesmente não a respondeu.

Dentre as parcialmente corretas, podemos destacar dois grupos de respostas: retrocesso de 2, sem colocar o sinal, o que o torna um número positivo; e avanço de -2, que indica ter havido uma movimentação correta sobre a reta numérica, acompanhada, porém, de uma confusão entre os termos "avanço" e "retrocesso". Em meio às respostas incorretas, podemos notar que os alunos ficaram presos às movimentações realizadas pelo caracol, indicando que houve avanços e retrocessos, e não consideraram o balanço final das movimentações realizadas.

No terceiro tópico da questão, foi solicitado aos alunos que representassem, por meio da reta dos inteiros, os movimentos feitos pelo caracol no primeiro item (PROJETO Araribá, 2006). Dentre os desenhos apresentados como resposta a essa alternativa, 24 estavam corretos, um parcialmente correto e onze incorretos.

Nas respostas incorretas, podemos perceber que a não congruência semântica entre a frase e o registro geométrico foi um dos principais fatores que conduziram os alunos ao insucesso. Vejamos um exemplo:

c) Represente, por meio da reta dos inteiros, as movimentos feitos por ele no item a.

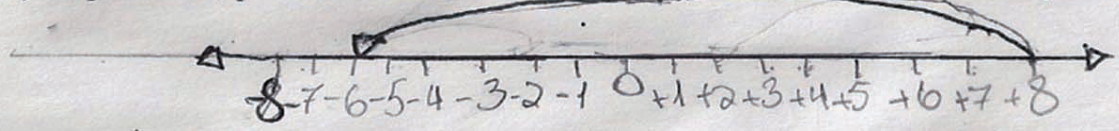

Figura 6: Resposta apresentada pelo aluno 24

No momento em que o aluno faz a conversão da linguagem natural "subiu 8 cm e escorregou 6" para o registro geométrico, a congruência semântica conduz à associação do (+8) ao (-6). No entanto, a equivalência referencial indica que, partindo do +8 , devemos voltar seis. Nesse caso, a congruência semântica destaca-se da equivalência referencial, e o sucesso da resposta depende da equivalência referencial. 
No último item dessa questão, os alunos deveriam representar, por meio da reta dos inteiros, os movimentos feitos pelo caracol no segundo item da questão. Do total dos alunos que participaram do teste, 23 fizeram o registro corretamente, dez de maneira incorreta e três deixaram a questão em branco. A maior parte dos desenhos incorretos estava relacionada à contagem inadequada dos espaços na reta numérica.

Passamos, agora, para a análise de uma segunda questão, a qual faz parte do mesmo teste do item anterior. Foi solicitado aos alunos que resolvessem a seguinte situação problema: "Pedro está jogando bolinhas de gude. Na primeira partida perde seis. Joga uma segunda partida. Depois dessas duas partidas, ele nem perdeu nem ganhou. O que aconteceu na segunda partida?" (PROJETO ARARIBÁ, 2006, p. 28). Na resposta a essa situação, dezoito alunos obtiveram êxito; dois disseram que "ele parou de jogar"; quatro apontaram que "ele perdeu bolinhas"; outros quatro deixaram a questão em branco; e oito apresentaram respostas variadas, tais como: "não ganhou nem perdeu bolinhas", "continua com a mesma percentagem de bolinhas", "- $6+(0)=0$ ", entre outras.

Nessa questão, contatamos que o fato da não congruência semântica entre a expressão e o seu registro contribuiu para um elevado índice de insucessos. Se a mesma situação fosse apresentada de outra forma, na qual houvesse uma congruência semântica entre a expressão e o seu registro, certamente o índice de acertos teria sido maior. Porém, a ausência de congruência semântica entre frase e expressão numérica conduziu muitos alunos a produzirem respostas incorretas.

A última questão que iremos analisar faz parte do teste aplicado no bloco da subtração a 36 dos 39 alunos que constituem a turma. Na questão, foi proposta aos alunos a seguinte situação: "Uma pessoa encontra-se em uma câmara frigorífica cuja temperatura é de - $8^{\circ} \mathrm{C}$. Ao sair, encontrará uma temperatura ambiente de $23^{\circ}$ C. Qual a variação de temperatura que essa pessoa terá de suportar?" (PROJETO Araribá, 2006, p. 28).

Dos 36 alunos que participaram do teste, apenas quatro responderam corretamente, 26 erraram a questão e seis não a responderam. Podemos observar, dentre as respostas incorretas, que quatorze alunos apontaram $15^{\circ} \mathrm{C}$ como a variação da temperatura para essa situação. Ou seja, os alunos, ao invés de subtrair (-8), acabaram adicionando (-8) para encontrar a variação da temperatura. Como já comentamos, isso ocorreu porque a subtração de números relativos significa trabalhar com operadores negativos que operam transformações de oposição. Nesse caso, os alunos sabiam que precisavam da operação de subtração, no entanto, não realizaram o jogo de sinais a fim de simplificar a expressão, obtendo, assim, uma soma.

Podemos analisar essa questão, também, sob a perspectiva da congruência semântica. A situação proposta é semanticamente congruente à expressão $+23-8$, 
mas, nesse caso, a congruência semântica se destaca da equivalência referencial, conduzindo a um resultado incorreto. De acordo com Duval, a maior parte dos insucessos cometidos pelos alunos nas atividades matemáticas está fortemente relacionada aos fenômenos da congruência semântica: "[...] a verdadeira fronteira, aquela que bloqueia muitos alunos é a congruência e a não congruência semântica no jogo da substituição de uma expressão a outra ou de uma representação a outra" (2012, p. 116).

Assim, nessa questão, como em outras apresentadas anteriormente, grande parte dos alunos seguiu o caminho da congruência semântica e não conseguiu obter sucesso nas suas respostas, uma vez que tal congruência se destacava da equivalência referencial.

\section{Considerações finais}

No ensino dos números relativos - mais especificamente, no ensino das suas operações de adição, multiplicação e subtração -, percebemos que as concepções que os alunos trazem, associando o número a uma grandeza, contribuem para a formação de entraves quando da passagem dos naturais aos inteiros relativos. Nos relativos, o conceito dessas operações precisa ser ampliado e ressignificado pelos alunos.

Pautados na teoria dos registros de representação semiótica, percebemos que muitas das dificuldades que observamos no processo de ensino e aprendizagem dos números relativos e das operações de adição, subtração e multiplicação podem ser explicadas em termos da noção de congruência semântica. Num problema cuja formulação não apresenta congruência semântica com a operação requerida na sua solução, tende a haver um índice de acerto significativamente menor em relação ao caso de um mesmo tipo de problema que mobiliza os mesmos conhecimentos matemáticos, mas que possui congruência semântica. A congruência semântica "impele" o aluno para um tipo de solução do problema. Em muitos casos, o fator determinante para que essa solução seja correta ou não vai depender da equivalência referencial, pois a solução encontrada por um aluno, em um problema congruente, somente vai ser correta (em geral) se tiver, também, equivalência referencial.

No ensino de matemática, são os problemas sem congruência semântica os mais importantes, porque são cognitivamente mais complexos. Não há porque fugir de problemas sem congruência semântica. São eles, em geral, oriundos de operações de conversões, que estão na base da ideia de aprendizagem de Duval: "Para não confundir um objeto e sua representação, quando a intuição direta do objeto 
mesmo não é possível, é necessário dispor de várias representações semioticamente heterogêneas deste objeto e coordená-las" (2004, p. 69).

Propor diferentes formulações coordenadas para um mesmo tipo de problema é, portanto, o caminho que ajuda a diminuir as dificuldades encontradas pelos alunos quando não há congruência semântica entre a sua formulação e as operações ou expressões empregadas na sua solução. A utilização de vários registros de representação semiótica e a atividade de conversão são importantes nesse processo, no sentido de conduzir o aluno à apropriação do objeto matemático.

\section{Aspects of semantic congruency present on relative whole numbers teaching}

\section{Abstract}

Teaching negative numbers may be strongly characterized by a kind of teaching based on the commercial model of gains and losses, in which the losses relate to subtraction and the gains to addition. This kind of "codification", regarding the processes of addition and subtraction, brings up a phenomenon studied by Raymond Duval in mathematics learning called semantic congruency. In teaching situations, concepts of addiction, multiplication and subtraction must be expanded from Natural to Relative Whole Numbers. Regarding this new teaching expansion, this article intends to analyze answers, based on the notion of semantic congruency, given by students of the $7^{\text {th }}$ grade of Junior High when asked about some specific questions.

Keywords: Negative numbers. Registration of representation. Semantic congruency.

\section{Notas}

1 Apoios do CNPq e da Capes.

$2 \mathrm{O} 7^{\circ}$ ano corresponde à antiga $6^{\mathrm{a}}$ série do ensino fundamental de oito anos.

3 Glaeser (1981) entende como modelo comercial a associação de um número positivo à ideia de um ganho/ lucro e de um número negativo à ideia de uma perda/prejuízo.

4 Essa frase pode ser substituída por outros produtos de dois inteiros, mas em todos os casos exigirá uma mudança inter-registro.

5 De acordo com Caraça, "[...] o homem tem tendência a generalizar e entender todas as aquisições do seu pensamento, seja qual for o caminho pelo qual essas aquisições se obtêm, e a procurar o maior rendimento possível dessas generalizações pela exploração metódica de todas as suas consequências. Todo o trabalho intelectual do homem é, no fundo, orientado por certas normas, certos princípios. Àquele princípio em virtude do qual se manifesta a tendência que acabamos de mencionar, daremos o nome de princípio de extensão" (1963, p. 10). 


\section{Referências}

ALVES, E. L.; MAIA, L. de S. L. Multiplicação e divisão de números inteiros: ensino-aprendizagem na EJA. In: CONFERÊNCIA INTERAMERICANA DE EDUCAÇÃO MATEMÁTICA, 13, Recife, 2011. Anais... Recife: Sbem, 2011. p. 1-11. CD-ROM.

CARAÇA, B. J. Conceitos fundamentais da matemática. Lisboa: Bertrand, 1963.

COLOMBO, J. A. A.; FLORES, C. R.; MORETTI, M. T. Registros de representação semiótica nas pesquisas brasileiras em educação matemática: pontuando tendências. Revista Zetetiké, Campinas, SP, v. 16, p. 41-72, 2008.

COQUIN-VIENNOT, D. Complexité mathématique et ordre d'aquisition: une hierarchie de conceptions à propos des relatifs. $R D M$, v. 6, n. 2-3, p. 133-192, 1985.

DUVAL, R. Registres de représentation sémiotique et fonctionnement cognitif da la pensée. Annales de Didactique et de Sciences Cognitives, Strasbourg, v. 5, p. 37-65, 1993.

. Semiosis y pensamiento humano: registros semióticas y aprendizajes intelectuales. Colombia: Peter Lang, 2004.

. Registros de representação semiótica e funcionamento cognitivo da compreensão em matemática. In: MACHADO, S. D. A. Aprendizagem em matemática. 2. ed. São Paulo: Papirus, 2005. p. 11-33.

. Diferenças semânticas e coerência matemática: introdução aos problemas de congruência. Trad. de Méricles Thadeu Moretti. Revista Eletrônica de Educação Matemática (Revemat), Florianópolis, v. 7, n. 1, p. 97-117, 2012. Disponível em: <http://www.periodicos.ufsc.br/index.php/ revemat>. Acesso em: 2 jan. 2012.

GLAESER, G. Epistemologie des nombres relatifs. RDM, v. 2, n. 3, p. 303-346, 1981.

MORETTI, M. T. A regra dos sinais para a multiplicação: ponto de encontro com a noção de congruência semântica e o princípio de extensão em matemática. Bolema - Boletim de Educação Matemática, UNESP, Rio Claro, v. 26, p. 691-714, 2012.

PASSONI, J. C. (Pré-) álgebra: introduzindo os números inteiros. 2002. Dissertação (Mestrado em Educação Matemática) - Pontifícia Universidade Católica de São Paulo, São Paulo, 2002.

PONTES, M. de O. Obstáculos superados pelos matemáticos no passado e vivenciados pelos alunos na atualidade: a polêmica multiplicação de números inteiros. Tese (Doutorado em Educação) - Universidade Federal do Rio Grande do Norte, Natal, 2010.

PROJETO Araribá. Matemática ( $6^{a}$ série). São Paulo: Moderna, 2006.

TEIXEIRA, L. R. M. Aprendizagem operatória de números inteiros: obstáculos e dificuldades. Revista Pró-Posição, Campinas, SP, Unicamp, v. 4, n. 1[10], p. 60-72, mar. 1993. 